\title{
COMPOSIÇÃO CENTESIMAL E LIPÍDICA DA CARNE DE OVINOS DO NORDESTE BRASILEIRO
}

\author{
PROXIMATE ANALYSIS AND LIPIDIC COMPOSITION OF LAMB MEAT \\ FROM NORTHEASTERN BRAZIL
}

\section{Jorge Fernando Fuentes Zapata ${ }^{1}$ Cynthia Monteiro Nogueira ${ }^{2}$ Larissa Mont'Alverne Jucá Seabra $^{3}$ Nelson Nogueira Barros ${ }^{4}$ Ângela Silva Borges ${ }^{5}$}

RESUMO

O objetivo desta pesquisa foi avaliar a composição centesimal e lipídica da carne de ovinos do Nordeste brasileiro. Para isso, foram utilizados 21 borregos, machos inteiros, sendo 10 animais $1 / 2$ Somalis Brasileira $\times 1 / 2$ Crioula $(S B-C)$ e 11 animais $1 / 2$ Santa Inês $\times 1 / 2$ Crioula (SI-C). Os animais receberam duas dietas durante a fase de amamentação: feno de capimgramão (Cynodon dactylon) + feno de leucena (Leucaena leucocephala) ad libitum (D1) e feno de capim-gramão + feno de leucena + concentrado com $20 \%$ de proteína bruta ad libitum (D2). Não foi observado o efeito dos genótipos nem do sistema de alimentação sobre a composição centesimal e lipídica da carne. Os valores de umidade, proteína, cinzas e gordura, variaram de 76,12 a 76,19\%, 19,19 a 19,46\%, 1,08 a 1,10\% e 2,01 a 2,39\%, respectivamente. Os valores de colesterol variaram de 54,43 a $60,05 \mathrm{mg}$ por $100 \mathrm{~g}$ de carne. Os ácidos graxos encontrados em maior quantidade na fração lipídica da carne dos animais estudados foram oleico, palmítico e esteárico. De acordo com os resultados obtidos, conclui-se que a carne de ovinos do Nordeste brasileiro apresenta uma composição centesimal e lipídica similar às carnes de ovinos de clima temperado.

Palavras-chave: pequenos ruminantes, dieta, colesterol, ácidos graxos.

\section{SUMMARY}

The objective of this study was to evaluate the proximate and lipidic compositon of lamb meat from tropical sheep reared in Northeastern Brazil. Twenty-one rams, ten $1 / 2$ Somalis Brasileira $1 / 2 \times$ Crioula $(S B-C)$ and 11 1/2 Santa Inês $\times 1 / 2$ Crioula (SI-C) were used. Two feeding regimes were utilized during weaning: grass hay (Cynodon dactylon) + leucena hay (Leucaena leucocephala) ad libitum (D1) and grass háy + leucena hay $+20 \%$ crude protein concentrate ad libitum (D2). It was not observed effect of crossbreed or feeding regime on proximate and lipidic composition of the meat. Moisture, protein, ash and fat values varied from 76.12 to $76.19 \%, 19.19$ to $19.46 \%$, 1.08 to $1.10 \%$ and 2.01 to $2.39 \%$, respectively. Cholesterol content ranged from 54.43 to $60.05 \mathrm{mg} / 100 \mathrm{~g}$ of meat. The more abundant fatty acids in lamb fat were oleic, palmitic and stearic. Based on these results, it can be concluded that lamb meat from Notheastern Brazil has proximal and lipidic compositions similar to that animals from temperate regions of the World.

Key words: Small ruminant, diets, cholesterol, fatty acids.

\section{INTRODUÇÃO}

A carne ovina é uma fonte de proteína de alto valor biológico e assim como a carne caprina, está presente na dieta das populações de quase todos os países, principalmente dos continentes africano e asiático (ALMEIDA, 1990). No Brasil, o consumo per capita de carne ovina não atinge $2 \mathrm{~kg} /$ habitante $/$ ano, sendo $0,17 \mathrm{~kg} / \mathrm{hab} / \mathrm{ano}$ no Nordeste e $1,8 \mathrm{~kg} / \mathrm{hab} /$ ano no Sul do País, enquanto na Austrália atinge 20kg/hab/ano (ROÇA, 1993).

Devido à atenção que o consumidor tem dado para a relação entre dieta e saúde, há uma crescente preocupação com o conteúdo de gordura e colesterol dos produtos de origem animal (HARRIS

\footnotetext{
${ }^{1}$ Químico Farmacêutico, Doutor, Professor Titular, Departamento de Técnologia dos Alimentos (DTA), Universidade Federal do Ceará (UFC), CP 12168, 60020-181, Fortaleza, CE. E-mail: zapata@ufc.br. Autor para correspondência.

${ }^{2}$ Engenheiro de Alimentos, Mestre, Bolsista do CNPq, DTA, UFC.

${ }^{3}$ Nutricionista, Mestre, Bolsista do CNPq, DTA, UFC.

${ }^{4}$ Médico Veterinário, Doutor, Pesquisador do CNPC-EMBRAPA, Sobral, CE.

${ }^{5}$ Aluno do Curso de Engenharia de Alimentos, Bolsista de Iniciação Científica CNPq, UFC.
} Recebido para publicação em 22.05.00. Aprovado em 07.11.00 
et al., 1993). Recomenda-se a redução da ingestão de gordura, principalmente as ricas em colesterol e ácidos graxos saturados e um aumento do consumo de ácidos graxos mono e poliinsaturados, com o propósito de diminuir o risco de obesidade, câncer e doenças cardiovasculares (JAKOBSEN, 1999). Com relação ao consumo de colesterol, é desejável uma ingestão de quantidades menores que $300 \mathrm{mg}$ por dia (USDA, 2000). A carne de ruminantes é considerada rica em ácidos graxos saturados e monoinsaturados, com pequenas quantidades de poliinsaturados (SINCLAIR et al. 1982). Para atender as atuais exigências dos consumidores, os estudos vêm-se direcionando para o aumento da massa muscular nas carcaças ovinas, com a diminuição do seu teor de gordura (SAÑUDO et al., 1998; TAHIR et al., 1994). Várias estratégias têm sido utilizadas para conseguir atender a procura dos consumidores por carne saudável, dentre elas a escolha da raça, do sexo e da dieta oferecida aos animais (MONTEIRO \& SHIMOKOMAKI, 1999).

A composição química da carne ovina varia com a categoria do animal e com a sua localização na carcaça (JARDIM, 1983). A raça e o sistema de alimentação também podem afetar as características químicas da carne (SAÑUDO $\boldsymbol{e t} \boldsymbol{a l}$., 1998; SAÑUDO et al., 2000). Sabe-se que, no rúmen, ocorre a hidrogenação de uma grande quantidade de ácidos graxos insaturados da dieta de modo que a carne de ruminantes, como os ovinos, apresentam maior quantidade de ácidos graxos saturados. O ácido linoléico (C18:2), que é o principal ácido graxo dos vegetais, encontra-se em quantidades muito pequenas na gordura corporal dos ruminantes (WOOD et al., 1999). Com relação ao conteúdo de colesterol e perfil de ácidos graxos da carne de animais do Nordeste do Brasil, existem poucos dados, sendo a maior parte destes provenientes de pesquisas com animais de clima temperado (RUSSO et al., 1999; HORCADA et al., 1998; SAÑUDO et al., 1998; ENSER et al., 1998; SAÑUDO $\boldsymbol{e}$ t al., 2000). O objetivo do presente trabalho foi analisar a composição centesimal e lipídica da carne ovina de animais provenientes de cruzas raciais comuns no Nordeste brasileiro submetidos a dois sistemas de alimentação.

\section{MATERIAL E MÉTODOS}

O estudo foi realizado no Departamento de Tecnologia de Alimentos da Universidade Federal do Ceará, em Fortaleza, em colaboração com o Centro Nacional de Pesquisa com Caprinos da EMBRAPA, Sobral, CE. Foram utilizados 21 borregos, machos inteiros, sendo 10 animais $1 / 2$
Somalis Brasileira $\times 1 / 2$ Crioula $($ SB-C) e 11 animais $1 / 2$ Santa Inês $\times 1 / 2$ Crioula (SI-C). Os animais foram mantidos com as respectivas mães até 15 dias de idade. Em seguida, foram retidos no aprisco e submetidos à amamentação controlada até os 70 dias, quando foi efetuado o desmame. No aprisco, os animais receberam duas dietas durante o restante da fase de amamentação: 9 animais (4 SB-C e 5 SI-C) receberam feno de capim-gramão + feno de leucena ad libitum (D1) e 12 animais (6 SB-C e 6 SI-C) receberam feno de capim-gramão + feno de leucena + concentrado com $20 \%$ de proteína bruta ad libitum (D2). Em seguida, os animais foram submetidos à engorda em confinamento, durante 70 dias, com dieta única para os dois grupos genéticos, formulada segundo o NRC (1985) para obtenção de ganho de peso de $200 \mathrm{~g} / \mathrm{animal} / \mathrm{dia}$. Os animais foram abatidos aos 140 dias de idade de acordo com as técnicas do RIISPOA (1997).

Após o resfriamento das carcaças, foram coletados, por desossa manual, os pernis das meias carcaças direitas os quais, após pesagem, foram envolvidos em filme de PVC e colocados em sacos plásticos individuais devidamente identificados e transportados em caixas de isopor com gelo até o Laboratório de Carnes do Departamento de Tecnologia de Alimentos da Universidade Federal do Ceará, em Fortaleza, CE.

As amostras foram submetidas às determinações de umidade, proteína, gordura e cinzas, realizadas de acordo com as normas analíticas da AOAC (1990), após serem homogeneizadas em multiprocessador. Para as análises, foram utilizados todos os músculos do pernil, tendo sido retirada a gordura externa visível.

Para as determinações de colesterol e perfil de ácidos graxos, fez-se inicialmente a extração da fração lipídica da carne segundo BLIGH \& DYER (1959). A determinação do colesterol foi realizada pelo método colorimétrico descrito por BOHAC et al. (1988) e a densidade ótica foi medida em espectrofotômetro a 490nm (ULTROSPEC 1000 Pharmacia/Biotech, Cambridge, Inglaterra). Os valores de absorbância foram transformados para mg de colesterol usando-se curva de calibração segundo SEARCY \& BERGQUIST (1960) preparada

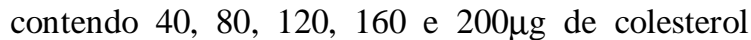
Sigma P.A. (St. Louis, MO). Para determinação do perfil de ácidos graxos, foram pesados $60 \mathrm{mg}$ da fração lipídica extraída da carne que, em seguida, foi submetida à metilação segundo MAIA \& RODRIGUEZ-AMAYA (1993), visando a preparação para a análise por cromatografia gasosa. Os valores foram expressos em função do percentual de ácidos graxos totais. Foi utilizado um 
cromatógrafo de gás Hewlett Packard 5890, série II, com detector seletivo de massa. O material foi separado em coluna capilar medindo $30 \mathrm{~m}$ e $0,25 \mathrm{~mm}$ de diâmetro e contendo DB-5-dimetylpolysiloxane como fase estacionária na forma de filme de $0,1 \mu \mathrm{m}$ de espessura. $\mathrm{O}$ aquecimento foi programado para elevar a temperatura de $35^{\circ} \mathrm{C}$ para $180^{\circ} \mathrm{C}$ à razão de $4^{\circ} \mathrm{C} / \mathrm{min}$ e de $180^{\circ} \mathrm{C}$ para $280^{\circ} \mathrm{C}$ à razão de $20^{\circ} \mathrm{C} / \mathrm{min}$.

O delineamento experimental foi inteiramente casualizado com arranjo fatorial $2 \times 2$ ( 2 genótipos $\times 2$ níveis de alimentação), sendo considerado um animal como unidade experimental. Desta forma, o número de repetições por grupo era de 4 para o SB-C/D1, 6 para SB-C/D2, 5 para o SIC/D1 e 6 para o SI-C/D2. Para verificar possíveis efeitos dos cruzamentos raciais e dos sistemas de alimentação utilizados sobre os parâmetros estudados, foi realizada a análise de variância dos dados, usando-se o MINITAB Statistc Software (MINITAB, 1995).

\section{RESULTADOS E DISCUSSÃO}

Não foi observado efeito dos genótipos nem do sistema de alimentação sobre os parâmetros estudados $(\mathrm{P}>0,05)$. Os valores médios de umidade, proteína e cinzas, no presente estudo, variaram de 76,12 a $76,19 \%, 19,19$ a $19,46 \%$ e 1,08 a $1,10 \%$ respectivamente (Tabela 1). Os valores de gordura variaram de 2,01 a 2,39\% (Tabela 2). GARCIA et al. (1998) testando diferentes dietas de confinamento, não encontraram efeito sobre a composição química do músculo $L$. dorsi de ovinos machos $1 / 2$ Texel $\times 1 / 2$ Sem Raça Definida (SRD). Estes autores encontraram valores de 74,96 a $75,99 \%$ para umidade, de 19,30 a 20,13\% para proteína, de 1,41 a

Tabela 1 - Valores médios (Média \pm erro padrão), referentes à umidade, proteína e cinzas da carne de pernil de borregos 1/2 Somalis Brasileira-Crioula (SB-C) e 1/2 Santa Inês- Crioula (SI-C), submetidos a dois sistemas de alimentação.

\begin{tabular}{llll}
\hline & \multicolumn{3}{c}{ Variáveis } \\
\cline { 2 - 4 } \multicolumn{1}{c}{ Fatores } & Umidade (\%) & Proteína (\%) & Cinzas (\%) \\
\hline Genótipo & & & \\
SB-C & $76,14 \pm 0,17$ & $19,19 \pm 0,11$ & $1,10 \pm 0,02$ \\
SI-C & $76,17 \pm 0,26$ & $19,46 \pm 0,14$ & $1,08 \pm 0,02$ \\
Médias & 76,14 & 19,32 & 1,09 \\
Alimentação & & & \\
D1 & $76,12 \pm 0,18$ & $19,32 \pm 0,16$ & $1,09 \pm 0,02$ \\
D2 & $76,19 \pm 0,24$ & $19,33 \pm 0,12$ & $1,08 \pm 0,02$ \\
Médias & 76,15 & 19,32 & 1,08 \\
\hline
\end{tabular}

Tabela 2 - Valores médios (Média \pm erro padrão), referentes à gordura e colesterol da carne de pernil de borregos $1 / 2$ Somalis Brasileira-Crioula (SB-C) e $1 / 2$ Santa InêsCrioula (SI-C), submetidos a dois sistemas de alimentação.

\begin{tabular}{lll}
\hline & \multicolumn{2}{c}{ Variáveis } \\
\cline { 2 - 3 } Fatores & Gordura $(\%)$ & Colesterol $(\mathrm{mg} / 100 \mathrm{~g})$ \\
\hline Genótipo & & \\
SB-C & $2,39 \pm 0,19$ & $59,46 \pm 3,00$ \\
SI-C & $2,01 \pm 0,14$ & $55,99 \pm 2,80$ \\
Médias & 2,20 & 57,72 \\
Alimentação & & \\
D1 & $2,13 \pm 0,13$ & $54,43 \pm 1,42$ \\
D2 & $2,23 \pm 0,19$ & $60,05 \pm 3,29$ \\
Médias & 2,18 & 57,24 \\
\hline
\end{tabular}

$3,00 \%$ para gordura e de 0,95 a $1,33 \%$ para cinzas, valores próximos dos encontrados no presente estudo. HORCADA et al. (1998), estudando o efeito do sexo sobre a composição química da carne ovina, não encontraram diferenças para os teores de umidade, proteínas e cinzas, que foram de $74,0 \%$, $20,9 \%$ e $1,0 \%$, respectivamente. Com relação ao teor de gordura, porém, observaram maiores proporções na carne das fêmeas $(3,54 \%)$ do que na dos machos (3,15\%). GARCIA et al. (1995a), encontraram 2,0\% de gordura no músculo Semimembranosus de ovinos. No presente estudo, apesar de não ter havido diferenças significativas $(\mathrm{P}>0,05)$, provavelmente pelo fato de os animais terem recebido a mesma dieta na fase de acabamento, pôde-se observar que os animais SI-C apresentaram teores de gordura ligeiramente menores do que os SB-C (Tabela 2). Isto pode ter ocorrido devido ao fato de os cordeiros da raça Santa Inês produzirem carcaças mais pesadas e com menos gordura, por serem animais de alta musculosidade (SAINZ, 1996).

Os valores médios de colesterol na carne ovina variaram de 54,43 a $60,05 \mathrm{mg}$ por $100 \mathrm{~g}$ (Tabela 2). GARCIA et al. (1995a) encontraram valores de colesterol de 50,0mg no músculo Semimembranosus de ovinos. Os mesmos autores encontraram em carne bovina e em coxa de frango sem pele, valores de 53,0mg e 65,0mg, respectivamente. Em carnes de caprinos SRD, o colesterol variou de 61,5 a $76,1 \mathrm{mg} / 100 \mathrm{~g}$, nos animais alimentados com uma dieta suplementada com cálcio (ALMEIDA et al., 1997).

No presente estudo, observou-se que o grupo que recebeu suplementação de concentrado (D2), apresentou valores de colesterol ligeiramente maiores. RUSSO et al. (1999), estudando o efeito de diferentes concentrados sobre o colesterol da carne 
ovina, encontraram em média 48,33mg de colesterol, sem terem observado algum efeito da dieta sobre este componente. MONTEIRO \& SHIMOKOMAKI (1999) também não observaram diferenças no teor de colesterol do músculo $L$. dorsi entre ovinos da raça Corriedale e da cruza Corriedale $\times$ Ile de France. Esses valores foram de 39,16 e $38,37 \mathrm{mg} / 100 \mathrm{~g}$ de carne e podem ser considerados baixos para este tipo de carne. Contudo, o aporte de $60 \mathrm{mg}$ de colesterol que forneceria uma refeição contendo $100 \mathrm{~g}$ de carne ovina do Nordeste do Brasil representa aproximadamente $20 \%$ do valor máximo aceito por órgãos internacionais (USDA, 2000).

Com relação ao perfil de ácidos graxos, foi encontrada uma maior proporção dos ácidos oléico $(48,83 \%$, em média), palmítico $(26,73 \%$, em média) e esteárico $(21,47 \%$, em média) conforme mostra a tabela 3 . Essa tendência também foi observada na carne ovina por WOOD et al. (1999), porém, com valores relativamente inferiores $(32,5 \%$ para o ácido oléico, $22,2 \%$ para o palmítico e $18,1 \%$ para o esteárico). Do mesmo modo, os principais ácidos graxos encontrados por SAÑUDO et al. (2000), no músculo Longissimus de cordeiros de duas raças espanholas e duas inglesas foram $\mathrm{o}$ palmítico, esteárico e oleico. De acordo com GAILI \& ALI (1985), estes são responsáveis por cerca de $90 \%$ do total de ácidos graxos da carne de ruminantes.

BESERRA (1983) também apontou como os principais ácidos graxos da carne de ovinos Deslanado Branco de Morada Nova, típicos da região Nordeste do Brasil, os ácidos oléico (40,0 a $47,0 \%)$, palmítico $(23,0$ a $25,5 \%)$ e esteárico $(18,0$ a 27,0\%). Da mesma maneira, os ácidos graxos encontrados em maior proporção por GARCIA $\boldsymbol{e t}$ al. (1995b), no músculo Semimembranosus de ovinos foram o oléico $(36,6 \%)$, palmítico $(25,7 \%)$ e esteárico $(15,0 \%)$

Tabela 3 - Valores médios referentes ao perfil de ácidos graxos (\%) da carne de pernil de borregos 1/2 Somalis Brasileira-Crioula (SB-C) e 1/2 Santa Inês- Crioula (SI-C), submetidos a dois sistemas de alimentação.

\begin{tabular}{lrcrrr}
\hline & \multicolumn{5}{c}{ Genótipo e Alimentação } \\
\cline { 2 - 6 } Ácidos graxos (\%) & SB-C/D1 & SB-C/D2 & SI-C/D1 & SI-C/D2 & Médias \\
\hline C14: 0 (mirístico) & 1,64 & 1,09 & 1,29 & 1,09 & 1,28 \\
C16:0 (palmítico) & 27,68 & 23,0 & 28,43 & 27,80 & 26,73 \\
C18:0 (esteárico) & 22,40 & 21,99 & 19,97 & 21,52 & 21,47 \\
C16:1 (palmitoléico) & 0,63 & 0,70 & 0,67 & 0,65 & 0,66 \\
C18:1 (oléico) & 41,43 & 44,91 & 45,02 & 43,94 & 48,83 \\
C18:1 trans (elaídico) & 1,86 & 1,97 & 1,66 & 2,16 & 1,91 \\
C18:2 (linoléico) & 1,80 & 2,70 & 1,42 & 1,55 & 1,87 \\
\hline
\end{tabular}

\section{CONCLUSÕES}

Os cruzamentos e os regimes de alimentação estudados não influenciam a composição da carne. Os ácidos graxos em maior quantidade na carne dos ovinos são o oléico, palmítico e esteárico. A carne de ovinos do Nordeste brasileiro se apresenta satisfatória na sua composição centesimal e lipídica, quando comparada com as carnes ovinas de animais de clima temperado.

\section{AGRADECIMENTO}

Ao Conselho Nacional de Desenvolvimento Científico e Tecnológico (CNPq) pelo apoio financeiro e ao Parque de Desenvolvimento Tecnológico da Universidade Federal do Ceará (PADETEC - UFC) pelo uso do cromatógrafo a gás na determinação do perfil de ácidos graxos.

\section{REFERÊNCIAS BIBLIOGRÁFICAS}

ALMEIDA, M.M.M. Estudo da composição química das carnes de caprinos e ovinos criados no sertão do Ceará. Fortaleza - CE, 1990. 78p. Dissertação (Mestrado em Tecnologia de Alimentos) - Curso de Pós-graduação em Tecnologia de Alimentos, Universidade Federal do Ceará, 1990 .

ALMEIDA, M.M.M., ZAPATA, J.F.F., MARTINS, C.B., $\boldsymbol{e} \boldsymbol{t} \boldsymbol{a l}$. Cholesterol and phopholipid levels in goat meat as affected by dietary calcium. Pesq Agropec Bras, v.32, n.5, p.555$558,1997$.

AOAC. ASSOCIATION OF OFFICIAL ANALYTICAL CHEMISTS. Official methods of Analysis of the Association of Official Analytical Chemists. 15 ed., Arlington, 1990. 1260p.

BESERRA, F.J. Efeito de diferentes planos nutricionais sobre o rendimento e qualidade das carcaças de ovinos da raça Morada Nova -Variedade Branca. Fortaleza - CE, 1983. 94p. Dissertação (Mestrado em Tecnologia de Alimentos) Curso de Pós-graduação em Tecnologia de Alimentos, Universidade Federal do Ceará, 1983.

BLIGH, E.G., DYER, W.J. A rapid method of total lipid extraction and purification. Can J Biochem Physiol, v.37, n.8, p.911-917, 1959.

BOHAC, C.E., RHEE, K.S. CROSS, H.R., et al Assessment of methodologies for colorimetric cholesterol assay of meats. J Food Sci., v.53, n.6, p.1642-1644, 1988

ENSER, M., HALLETT, K.G., HEWETT, B., et al. Fatty acid content and composition of uk beef and lamb muscle in relation to production system and implications for human nutrition. Meat Science, v.49, n.3, p.329-341, 1998

GAILI, E.S., ALI, A.E. Meat from sudan desert sheep and goats: part 2 - composition of the muscular and fatty tissues. Meat Science, v.13, p.229-136, 1985. 
GARCIA, C.A., SOBRINHO, A.G.S., ROÇA. R.O. Mensurações e análise química do músculo longissimus dorsi de ovinos confinados sob diferentes dietas. In: REUNIÃO DA SOCIEDADE BRASILEIRA DE ZOOTECNIA, 1998. Botucatu, SP. Anais... Botucatu : Sociedade Brasileira de Zootecnia. 1998. p.582-584.

GARCIA, P.T., CASAL, J.J., MARGARIA, C.A., et al. Cholesterol content in different meats. In: ANNUAL INTERNATIONAL CONGRESS OF MEAT SCIENCE AND TECHNOLOGY, 41, 1995, San Antonio, Texas, USA. Proceedings... San Antonio, Texas, USA : American Meat Science Association, 1995a. V.II. 678p. p.54-55.

GARCIA, P.T., CASAL, J.J., MARGARIA, C.A., $\boldsymbol{e t}$ al. Lipids from lamb meat. In: INTERNATIONAL CONGRESS OF MEAT SCIENCE AND TECHNOLOGY, 41, 1995, San Antonio, Texas, USA. Proceedings... San Antonio, Texas, USA : American Meat Science Association, August, 1995b. V.II. 678p. p.56-57.

HARRIS, K.B., CROSS, H.R., POND W.G., et al. Effect of dietary fat and cholesterol concentrations of growing pigs selected for high or low serum cholesterol. J Anim Sci, v.71, p.807-810, 1993

HORCADA, A., BERIAIN, M.J., PURROY, A., et al. Effect of sex on meat quality of spanish lamb breeds (Lacha and Rasa Aragonesa). Animal Science, v.67, p.541-547, 1998.

JAKOBSEN, K. Dietary modifications of animal fats: Status and future perspectives. Fett Lipid, v.101, n.12, p.475-483, 1999.

JARDIM, W.R. Os ovinos. 4 ed. São Paulo : Nobel, 1983. 193p.

MAIA, E.L., RODRIGUEZ-AMAYA, D.B. Avaliação de um método simples e econômico para a metilação de ácidos graxos com lipídios de diversas espécies de peixes. Ver Inst Adolfo Lutz, v.53 n.1/2, p.27-35, 1993

MINITAB. Mini manual. A beginner's guide to MINITAB statistics software. USA : State College, PA, 1995. 562p.

MONTEIRO, E.M., SHIMOKOMAKI, M. Influência do genótipo nos lipídios totais e na fração insaponificável da carne de cordeiros. Ciência Rural, Santa Maria, v.29, n.3, p.545-548, 1999 .

NRC. Nutrient requirements of sheep. National Research Council. $6^{\text {th }}$ Revised edition. Washington, D.C., USA: National Academy of Sciences, 1985. 112p.
RIISPOA. Regulamento da Inspeção Industrial e Sanitária de Produtos de Origem Animal. Brasília-DF : Ministério da Agricultura, 1997. 35p.

ROÇA, R.O. Alternativas de aproveitamento da carne ovina. Revista Nacional da Carne, n.201, p.53-60, 1993.

RUSSO, C., PREZIUSO, G., CASAROSA, L., et al. Effect of diet energy source on the chemical-physical caracteristics of meat and depot fat of lamb carcasses. Small Ruminant Research, v.33, n.1, p.77-85, 1999.

SAINZ, R.D. Qualidade das carcaças e da carne ovina e caprina. In: REUNIÃO ANUAL DA SOCIEDADE BRASILEIRA DE ZOOTÉCNIA, 1996, Fortaleza, CE. Anais... Fortaleza : Sociedade Brasileira de Zootecnia. 1996. v.33. p.3-19.

SAÑUDO, C., SIERRA, I., OLLETA, J.L., et al. Influence of weaning on carcass quality, fatty acid composition and meat quality in intensive lamb production systems. Animal Science, n.66, p.175-187, 1998.

SAÑUDO, C., ENSER, M.E., CAMPO, M.M., et al. Fatty acid composition and sensory characteristic of lamb carcasses from Britain and Spain. Meat Science, v.54, p.339-346, 2000.

SEARCY, R.L., BERGQUIST, L.M. A new color reaction for the quantitation of serum cholesterol. Clinica Chimica Acta, Amsterdam, 5, p.192-199, 1960.

SINCLAIR, A.J., SLATTERY, W.J., O'DEA, K. The analysis of polyunsaturated fatty acida in meat by capillary gas-liquid chromatography. J Sci Food Agric, v.33, p.771-776, 1982.

TAHIR, M.A., AL-JASSIM, A.F., ABDULLA, A.H.H. Influence of live weight and castration on distribution of meat, fat and bone in the carcass of goats. Small Ruminant Research, v.14, p.219-223. 1994.

USDA. United States Department of Agriculture. Dietary guidelines for americans. Fifth Edition, 2000. Capturado em 04 jun. 2000. Online. Disponível na Internet: http://www.usda.gov/cnpp.

WOOD, J.D., ENSER, M., FISHER, A.V, et al. Manipulating meat quality and composition. Proceedings of the Nutrition Society, v.58, p.363-370, 1999. 